\title{
Os Impactos da Alteração da Contribuição Previdenciária Patronal para a Indústria *
}

\author{
Nelson Leitão Paes \\ Professor - PIMES (UFPE) \\ Endereço para contato: Av. Prof. Morais Rego, s/n - Cidade Universitária - Recife-PE \\ CEP: 50670-901 -E-mail: nlpaes@yahoo.com.br
}

Recebido em 18 de dezembro de 2011 . Aceito em 16 de agosto de 2012.

\begin{abstract}
Resumo
Por variadas razões, a indústria brasileira vem perdendo competitividade interna e externa. Lançado recentemente, o programa Brasil Maior contempla, entre outras ações, a alteração da incidência da contribuição previdenciária patronal de alguns setores, que deixa de incidir sobre a folha de pagamento e passa para a receita bruta (MP 540/2011). Este artigo estimou os efeitos desta mudança, considerando uma elevação de $20 \%$ nas alíquotas da COFINS para se manter a neutralidade arrecadatória. Os resultados sugerem que não haverá grandes consequências macroeconômicas, embora o setor industrial apresente forte crescimento do produto e emprego, com pequenas reduções para a agricultura e serviços.
\end{abstract}

\section{Palavras-Chave}

reforma tributária, contribuição previdenciária, bem-estar

\begin{abstract}
For various reasons, the Brazilian industry is losing internal and external competitiveness. Recently launched the program "Brasil Maior" includes, among other actions, the change in the incidence of employer pension contributions of some sectors, leaving the incidence on the payroll to focus into the gross revenue (MP 540/2011). This paper has estimated the impact of this change, considering a $20 \%$ increase in rates of COFINS to maintain tax neutrality. The results suggest there will not be major macroeconomic consequences, although the industrial sector showed strong growth of output and employment, with small reductions in agriculture and services.
\end{abstract}

\section{Keywords}

tax reform, social security contribution, welfare

\section{JEL Classification}

$\mathrm{H} 22, \mathrm{H} 25, \mathrm{H} 32$

- O presente trabalho foi realizado com apoio do CNPq, Conselho Nacional de Desenvolvimento Científico e Tecnológico - Brasil. 


\section{Introdução}

O custo do trabalho no Brasil é considerado relativamente alto, embora exista grande discrepância dentro da literatura da sua exata magnitude. Alguns autores, como Pastore (2005), ${ }^{1}$ estimam um valor superior à própria folha de pagamento, com os encargos correspondendo a pouco mais de $103 \%$ do salário. Tamanho custo tem reflexo direto na economia, gerando grande ineficiência. Os preços tendem a se situar em patamar mais elevado, a alocação dos fatores de produção tende a ser mais intensiva em capital do que deveria, além de gerar dificuldades adicionais para os setores intensivos em mão de obra. Uma das principais consequências é a diminuição da competitividade do país.

A situação torna-se mais grave para a indústria. Este é o setor mais exposto à competição externa, dentro e fora do país. Setores intensivos em trabalho no país precisam competir com empresas chinesas e indianas, onde o custo do trabalho é uma fração do que é pago pelas empresas nacionais. ${ }^{2}$

Em recente pesquisa da CNI (2011), com uma amostra de 1.520 empresas, constatou-se que $28 \%$ concorrem com empresas chinesas no mercado interno. Deste grupo, $45 \%$ perderam mercado e $41 \%$ mantiveram sua fatia de mercado inalterada. Por outro lado, dentre as empresas que exportam, $52 \%$ concorrem com as chinesas. Das que enfrentam a disputa com os produtos chineses no mercado exterior, $67 \%$ estão perdendo clientes, percentual que sobe $80 \%$ nos setores têxteis, máquinas e equipamentos, além de produtos de metal, com $80 \%$. No setor de calçados, $21 \%$ das empresas brasileiras pararam de exportar.

A consequência tem sido a perda de participação da indústria na economia brasileira pela expansão das importações, além da dificuldade de exportar para parceiros tradicionais. A balança comercial brasileira para produtos industriais de média-baixa intensidade tecnológica, após vários anos apresentando superávit, tornou-se deficitária em 2011. O saldo comercial brasileiro na indústria de transformação está ficando cada vez mais negativo. No primeiro trimestre de 2008, o

1 Porém tais números não são unânimes na literatura. Por exemplo, o DIEESE (1997) estima um valor de 30,89\% e Noronha, De Negri e Artur (2006), um valor intermediário de 53,93\%.

2 Os mecanismos de regulação no mercado de trabalho chinês são quase que inexistentes (Levy, Nonneberg e De Negri (2006)) 
saldo era de -US\$ 204 milhões; esse saldo negativo caiu para -US\$ 7,1 bi e -US\$ 10 bi em igual período de 2010 e 2011 respectivamente. É claro que uma série de outros fatores contribui para a indústria brasileira estar em posição tão difícil para competir, como a forte valorização do real, juros elevados, infraestrutura precária e alta carga tributária.

De forma a tentar reduzir as dificuldades que se colocam para a indústria, o governo brasileiro lançou recentemente o programa Brasil Maior, que contempla uma série de ações voltadas para incrementar a competitividade da indústria nacional. Trata-se de um programa amplo, que contempla, entre outros tópicos, incentivos à inovação e tecnologia, redução do custo do crédito, desoneração de investimentos e alteração provisória e experimental (até o final de 2012) da cobrança das contribuições previdenciárias patronais dos setores de vestuário e acessórios, calçados, móveis e softwares, que deixará de incidir sobre a folha de pagamento e passará a ser calculada sobre a receita bruta (Medida Provisória no 540 de 02/08/2011). Este artigo se concentra neste último aspecto, buscando estimar os resultados da ampliação da eliminação de contribuição patronal sobre a folha de pagamento para todo o setor industrial, em troca de aumento na tributação sobre o consumo.

Assim, constrói-se um modelo de equilíbrio geral que permitirá realizar simulações sobre as alterações tributárias propostas e estimar os principais resultados dessa mudança. O modelo foi construído privilegiando-se o lado produtivo, que conta com 57 setores, os mesmos das Contas Nacionais, e mais as importações para obter resultados detalhados para cada setor. Do lado dos consumidores temos uma família representativa, além do governo, de forma que é possível acompanhar o comportamento da arrecadação. O modelo foi calibrado com dados das Contas Nacionais 2008.

Os resultados sugerem que do ponto de vista agregado, não haverá grandes consequências macroeconômicas, apenas a expansão do emprego, mas sem afetar significativamente produto, consumo, arrecadação e investimento. Do lado setorial, as modificações são muito mais intensas, com a reforma beneficiando a maioria dos setores industriais, atualmente muito mais tributado do que os demais segmentos da economia nacional. Porém, o balanceamento entre ganhadores e perdedores é bastante assimétrico, dada a concentração 
da desoneração e a dispersão dos custos associados ao incremento da tributação sobre o consumo. Enquanto os principais ganhadores experimentam aumentos de mais de $5 \%$, os perdedores apresentam reduções máximas em torno de $1,5 \%$.

Assim, depois desta introdução, a seção 2 apresenta uma breve revisão da literatura sobre a aplicação de modelos neoclássicos de equilíbrio geral a mudanças tributárias. A seção 3 mostra o modelo a ser utilizado, enquanto a seção 4 detalha a calibragem com os dados da economia brasileira. A seção 5 introduz a proposta de eliminação da contribuição patronal sobre a folha de pagamento para a indústria com o correspondente aumento na tributação sobre o consumo. A seção 6 traz os resultados com foco nas principais variáveis macroeconômicas e na evolução do produto e emprego setorial. Finalmente, a seção 7 apresenta as principais conclusões.

\section{Revisão da Literatura}

Modelos de equilíbrio geral têm tido vasta aplicação econômica, principalmente em áreas como finanças públicas, distribuição de renda, política energética e de meio ambiente, entre outras.

$\mathrm{Na}$ área de finanças públicas, alguns dos primeiros modelos de equilíbrio geral computável nos Estados Unidos foram desenhados para examinar questões relativas à reforma tributária (Shoven e Whalley, 1984). Uma série de autores se debruçou sobre o tema a partir da contribuição inicial de Fullerton (1982). ${ }^{3}$ Em linhas gerais, a literatura se baseou no modelo neoclássico de crescimento para buscar direções qualitativas e quantitativas dos efeitos de reformas ou mudanças tributárias.

Um exemplo interessante da interação entre artigos acadêmicos e discussões sobre reforma ocorreu no âmbito do legislativo norte-americano com o projeto conduzido pelo Comitê Conjunto de Tributação (JCT) em 1996. Este projeto revisou o resultado de nove modelos de simulação para a análise de propostas de reformas tributárias. O trabalho do JCT culminou em uma conferência em janeiro de 1997, quando os artigos foram apresentados. O objetivo do encon-

3 Destacam-se os trabalhos de Auerbach e Kotlikoff (1987), Fullerton e Rogers (1993) e Altig et al.(2001). 
tro foi o de aumentar o conhecimento dos técnicos e acadêmicos dos efeitos macroeconômicos de possíveis alterações tributárias. Taylor (1997) fez um breve sumário dos trabalhos e de como os nove modelos foram utilizados para comparar duas propostas diferentes. A primeira supõe a introdução de um imposto abrangente sobre a renda, o qual eliminaria todas as deduções mantendo apenas um valor mínimo de isenção, enquanto a segunda pressupõe um imposto amplo sobre o consumo, que poderia ser modelado como um imposto sobre valor adicionado ou como um tributo sobre as vendas. Se adotado o imposto sobre a renda, o imposto sobre o consumo seria eliminado, enquanto se adotado o imposto sobre o consumo, o da renda seria eliminado. Os resultados dessas duas estruturas tributárias foram então comparados com a estrutura atual, tomada como base.

Modelos neoclássicos de equilíbrio geral podem ser usados em política tributária para aplicações menores que não envolvam necessariamente grandes reformas tributárias. Por exemplo, a introdução do Imposto sobre Valor Adicionado (IVA), mesmo quando este não cobre toda a economia, pode ter seus efeitos previstos por esta abordagem. A análise de Bovenberg (1987) sobre diferentes implementações do IVA e suas implicações sobre a incidência tributária teve importantes efeitos sobre reformas tributárias conduzidas por numerosos países. Esta última forma de tratar a questão está mais próxima do objetivo deste trabalho, que não trata de uma reforma do sistema de tributos no Brasil, mas apenas de uma alteração pontual. Assim, mesmo para alterações tributárias menores, os modelos de equilíbrio geral podem também ser utilizados.

A literatura nacional sobre simulações de alterações tributárias desenvolveu-se a partir da segunda metade da década de 90 , conforme as discussões sobre reforma tributária avançavam no Congresso Nacional. Um primeiro artigo sobre o tema, Araújo e Ferreira (1999), buscava examinar os efeitos de duas propostas em discussão no Congresso - a da CERF (Comissão executiva de Reforma Fiscal) e a PEC 046-A/95 do Deputado Luiz Roberto Ponte. Tratava-se de um modelo simples, agregado, com o objetivo de analisar os efeitos macroeconômicos das duas propostas. O passo seguinte foi incorporar heterogeneidade às famílias, permitindo alguma análise sobre questões distributivas. Paes e Bugarin (2006) examinaram os efeitos da Emenda Constitucional no 42 de 2003, contemplando não só os aspectos macroeconômicos, mas também trazendo considerações 
acerca dos efeitos sobre a desigualdade de renda e a progressividade do sistema tributário nacional.

Trabalhos mais recentes como Pereira e Ferreira (2009), Salami e Fochezatto (2009) e Paes (2011) também se debruçam sobre os efeitos de alterações tributárias, trazendo mais complexidade aos modelos ou abordando a questão sob uma ótica diferente. É precisamente o que faz Salami e Fochezatto (2009), que usam o modelo de gerações superpostas (OLG) para análise de longo prazo de mudanças na tributação em uma economia aberta. O uso de modelos OLG traz uma nova dimensão à análise, já que permite comparar as variações de bem-estar entre gerações, e não somente pela renda como em Paes e Bugarin (2006). Pereira e Ferreira (2009) ainda adotam um modelo mais agregado, mas incorporam algumas novidades na modelagem das firmas, como a introdução de externalidades positivas no estoque de capital e diferenciação entre capital público e privado, o que traz maior realismo ao modelo como enfatizado pelos autores. Por fim, Paes (2011), em modelo mais sofisticado, apresenta um artigo em que a diferenciação se dá no nível das firmas e não mais sobre as famílias. Esta nova abordagem permite a análise de impactos setoriais das mudanças tributárias. $\mathrm{O}$ autor aplica ao modelo a PEC 233/2008, buscando avaliar os efeitos desta proposta sobre os segmentos econômicos.

Este artigo continua na linha evolutiva da literatura nacional, ao modificar o modelo de Paes (2011), incorporando um setor externo como em Salami e Fochezatto (2009), embora de maneira mais simples do que a utilizada por estes autores. O objetivo similar é o de analisar os efeitos macroeconômicos e setoriais da eliminação da contribuição patronal da indústria compensada pela elevação da tributação sobre o consumo.

\section{Metodologia}

Considere uma economia baseada no modelo neoclássico de crescimento discreto. Por hipótese, a economia é aberta, determinística e com população e tecnologia constantes. Há informação perfeita por parte de todos os agentes econômicos e os mercados são completos. As famílias são formadas por um agente representativo, enquanto que a produção é realizada por 57 firmas produtoras de bens inter- 
mediários e uma firma produtora do único bem final nesta economia. Uma parte da produção dos bens intermediários é destinada à exportação, quando não há a incidência de imposto sobre o produto, e as importações se constituem, de maneira agregada, como mais uma firma intermediária e que são tributadas.

As famílias fornecem mão de obra e alugam capital para as firmas intermediárias, que, em troca, pagam salários e juros. As famílias buscam alocar o seu tempo entre consumo e lazer, de maneira a maximizar o seu bem-estar, estando, entretanto, sujeita a restrições orçamentárias. Todos os tributos são pagos pelas firmas produtoras de bens intermediários. Tais firmas são competitivas e contratam mão de obra e capital das famílias. A firma produtora do bem final também é competitiva e agrega os bens intermediários. O governo arrecada imposto sobre a produção das firmas intermediárias, sobre o rendimento do trabalho e sobre o rendimento do capital. Com tais recursos faz transferências e adquire parte do bem final.

\subsection{Famílias}

O problema das famílias consiste em maximizar a sua utilidade, dada por uma função logarítmica (1), respeitando a sua restrição orçamentária (2).

$$
\begin{aligned}
& U_{i}=\sum_{t=0}^{\infty} \beta^{t}\left[\ln \left(c_{t}\right)+\gamma \ln \left(1-h_{t}\right)\right] \\
& P_{t}\left[c_{t}+k_{t+1}-(1-\delta) k_{t}\right]=w_{t} h_{t}+r_{t} k_{t}+P_{t} T_{t}
\end{aligned}
$$

Em que $\beta$ denota o fator de desconto intertemporal, $y$ o peso do lazer na função utilidade, $\delta$ é a depreciação, $P_{t}$ é o preço do bem de consumo final, $c_{t}$ é o consumo, $h_{t}$ as horas trabalhadas pela família, $w_{t}$ é o salário, $r_{t}$ é o preço do aluguel do capital, $k_{t}$ é o estoque de capital e $T_{t}$ são as transferências do governo para as famílias.

Das condições de primeira ordem, obtemos as equações para a trajetória ótima do consumo e do trabalho escolhidas pelas famílias:

$$
c_{t+1}=\beta\left[(1-\delta)+\frac{r_{t+1}}{P_{t+1}}\right] \cdot c_{t}
$$




$$
h_{t}=1-\gamma \frac{P_{t} c_{t}}{w_{t}}
$$

\subsection{Firmas Intermediárias}

As firmas produtoras de bens intermediários são competitivas e, assim, tomam salários e juros como dados. Portanto, a firma escolhe as quantidades de insumos e produto que maximizam os seus lucros. A função de produção é do tipo Cobb-Douglas:

$$
y_{j t}=A_{j} k_{j t}^{\alpha_{j}} h_{j t}^{1-\alpha_{j}}
$$

Aqui $\alpha_{j}$ é a participação do capital na renda no setor $j, y_{j t}$ é o produto da firma do $\operatorname{setor} j, A_{j}$ é a produtividade do setor $j, k_{j t}$ é o estoque de capital da firma do setor $j$ e $h_{j t}$ é o número de horas trabalhadas na firma do setor $j$. O lucro da firma do setor $j$ é dado por:

$$
\pi_{j t}=\left(1-\tau_{j t}\right)\left(1-\alpha_{j}^{e}\right) p_{j t} y_{j t}+\alpha_{j}^{e} p_{j t} y_{j t}-\left(1+\tau_{h t}\right) w_{t} h_{j t}-\left(1+\tau_{k t}\right) r_{t} k_{j t}
$$

Onde $p_{j t}$ é o preço do bem intermediário $j, \alpha_{j}^{e}$ é a fração do produto que é exportada, $\tau_{j t}, \tau_{h t}$ e $\tau_{k t}$ são, respectivamente, as alíquotas dos impostos sobre a produção, renda do trabalho e renda do capital. Da condição de maximização de lucros e lucro zero obtemos:

$$
\begin{aligned}
& r_{t}=\frac{p_{j t}\left(1-\tau_{j t}+\alpha_{j}^{e} \tau_{j t}\right) A_{j} \alpha_{j} k_{j t}^{\alpha_{j}-1} h_{j t}^{1-\alpha_{j}}}{\left(1+\tau_{k t}\right)} \\
& w_{t}=\frac{p_{j t}\left(1-\tau_{j t}+\alpha_{j}^{e} \tau_{j t}\right) A_{j}\left(1-\alpha_{j}\right) k_{j t}^{\alpha_{j}} h_{j t}^{-\alpha_{j}}}{\left(1+\tau_{h t}\right)}
\end{aligned}
$$




\subsection{Firma Produtora de Bem Final}

A firma produtora do bem final é competitiva e a sua produção ocorre combinando a parte da produção dos bens intermediários destinados ao mercado interno (57 setores) e as importações, usando a seguinte tecnologia:

$$
Y_{t}=\left\{\sum_{j=1}^{58}\left[\left(1-\alpha_{j}^{e}\right) y_{j t}\right] \frac{1}{\lambda_{f}}\right\}^{\lambda_{f}}
$$

Onde $1<\lambda_{f}<\infty$ é a elasticidade de substituição entre os insumos intermediários. A maximização de lucros

$$
\pi_{t}=P_{t} Y_{t}-\sum_{j=1}^{58} p_{j t}\left(1-\alpha_{j}^{e}\right) y_{j t}
$$

Implica:

$$
\left(\frac{P_{t}}{p_{j t}}\right)^{\frac{\lambda_{f}}{\lambda_{f}-1}}=\frac{\left(1-\alpha_{j}^{e}\right) y_{j t}}{Y_{t}}
$$

De acordo com (10), a demanda pelo bem intermediário $j$ é uma função decrescente do seu preço relativo e uma função crescente do produto agregado. Usando (9) e (10), encontramos uma relação entre o preço do bem final e os preços dos bens intermediários:

$$
P_{t}=\left[\sum_{j=1}^{58} p_{j t}^{\frac{1}{1-\lambda_{f}}}\right]^{1-\lambda_{f}}
$$




\subsection{Governo}

O governo arrecada impostos para financiar seus gastos e transferências. A restrição orçamentária do governo é dada por:

$$
P_{t}\left(g_{t}+T_{t}\right)=\sum_{j=1}^{58} \tau_{j t} p_{j t}\left(1-\alpha_{j}^{e}\right) y_{j t}+\tau_{h t} w_{t} h_{t}+\tau_{k t} r_{t} k_{t}
$$

\subsection{Equilibrio}

No equilíbrio, as famílias escolherão as sequências $\left\{c_{t}, h_{t}, k_{t}\right\}$ que maximizam sua utilidade sujeita à restrição orçamentária. Por sua vez, as firmas escolhem $\left\{k_{j t}, h_{j t}\right\}$ de forma a maximizar seus lucros.

Definição 1. O sistema de preços é formado pelas sequências de preços $\left\{p_{j t} / P_{t}\right\}$ dos bens intermediários, $\left\{w_{t} / P_{t}\right\}$ do salário real e $\left\{r_{t} / P_{t}\right\}$ do retorno real do estoque de capital que obedece em equi líbrio às relações (7), (8), (11) e (12).

Definição 2. Uma alocação plausível é uma sequência de $\left\{c_{t}, h_{t}, k_{t}\right\}$ que satisfaz a restrição agregada:

$$
c_{t}+\left[k_{t+1}-(1-\delta) k_{t}\right]+g_{t}=Y_{t}
$$

No equilíbrio a oferta de capital e trabalho deve igualar a demanda aos preços de mercado:

$$
\begin{aligned}
& k_{t}=\sum_{j=1}^{57} k_{j t} \\
& h_{t}=\sum_{j=1}^{57} h_{j t}
\end{aligned}
$$




\subsection{Solução do Modelo}

Para calcular o equilíbrio, deve-se encontrar a solução para o sistema de equações composto por (3), (4), (7), (8), (10), (11), (13), (14), (15) e (16), de forma a se obter as trajetórias de $\left\{c_{1}, h_{t}, h_{j t}, k_{t}, k_{j t}, p_{j t} / P_{t}, w_{t} / P_{t}, r_{j} / P_{t}, Y_{t}, T_{t}\right\}$, dada a condição inicial $k_{0}$.

Utilizou-se o algoritmo de Broyden no software MATLAB para o cálculo do equilíbrio, supondo um período de transição equivalente a 60 anos.

\section{Calibragem}

A calibragem utilizou-se basicamente dos dados das Contas Nacionais do IBGE referentes ao ano de 2008. Normalizou-se o produto do bem final como $\mathrm{Y}=100$ e foram considerados como produtores de bens intermediários os 57 setores contemplados nas Contas Nacionais mais o setor de importados.

\subsection{Contas Nacionais}

Segundo as Contas Nacionais, a relação consumo/PIB, gastos do governo/PIB e investimento/PIB em 2008 foi de 59,04\%, 20,23\% e $20,73 \%$, respectivamente. As horas de trabalho foram fixadas em 0,25 , ou seja, o equivalente a um regime de trabalho de 44 horas semanais. ${ }^{4}$ A taxa de retorno do capital, $r_{t}$, foi igualada à taxa SELIC ao final de $2008,13,75 \%$. Já a distribuição do produto entre os setores foi obtida somando-se o valor adicionado de cada setor com os impostos indiretos (valor adicionado bruto), e dividindo-se este total pelo produto. Os valores encontrados estão dispostos na Tabela A.l do Anexo, coluna "valor adicionado (\%PIB)".

Finalmente, a participação da renda do capital na renda total $\left(\alpha_{j}\right)$ pode ser obtida dividindo o excedente operacional bruto em cada setor pelo seu valor adicionado. A participação das exportações no produto final $\left(\alpha_{j}^{e}\right)$ também pode ser obtida das Contas Nacionais. Os valores encontrados também estão na Tabela A.l do Anexo.

4 Para este modelo, preferiu-se trabalhar com a relação total de horas trabalhadas por total de horas semanais. 


\subsection{Tributação}

A carga tributária foi dividida em três grandes grupos de fatos geradores: renda do trabalho, produção e renda do capital. Cada setor terá alíquotas diferenciadas de tributos sobre a produção, mas estarão sujeitas a uma única alíquota do tributo sobre a renda do capital e a renda do trabalho.

A distribuição da carga fiscal por fato gerador foi efetuada com dados das Contas Nacionais em 2008.

Tabela 1 - Resumo da distribuição da carga tributária

\begin{tabular}{|l|c|}
\hline \multicolumn{1}{|c|}{ Fato gerador } & Percentual do PIB \\
\hline Imposto sobre a renda do trabalho & $11,88 \%$ \\
\hline Imposto sobre a renda do capital & $7,26 \%$ \\
\hline Imposto sobre o consumo & $15,80 \%$ \\
\hline Carga tributária & $34,94 \%$ \\
\hline
\end{tabular}

Fonte: Elaboração dos autores com dados das Contas Nacionais 2008.

De posse da distribuição da arrecadação pode-se calcular as alíquotas tributárias do modelo. Iniciando-se pela tributação da renda do trabalho, obtemos $\hat{o}_{h}$, dividindo-se a arrecadação sobre a renda do trabalho pela participação da renda do trabalho ${ }^{5}$ na renda total:

$$
\frac{\tau_{h}}{\left(1+\tau_{h}\right)}=\frac{\text { Arrec.Trab. }}{\frac{\sum_{j=1}^{57}\left(1-\tau_{j}+\alpha_{j}^{e} \tau_{j}\right)\left(1-\alpha_{j}\right) p_{j} y_{j}}{Y}}
$$

O que nos fornece $\tau_{h}=30,12 \%$. Em relação à tributação do capital, obtemos $\tau_{k}$, dividindo-se a arrecadação sobre a renda do capital pela participação da renda do capital na renda total:

$$
\frac{\tau_{k}}{\left(1+\tau_{k}\right)}=\frac{\text { Arrec.Capital }}{\frac{\sum_{j=1}^{57}\left(1-\tau_{j}+\alpha_{j}^{e} \tau_{j}\right) \cdot \alpha_{j} \cdot p_{j} y_{j}}{Y}}
$$

5 O rendimento misto foi incluído como rendimento do trabalho. Segundo o IBGE (2006), a denominação rendimento misto é devido à natureza do ganho do trabalhador que não pode ser especificada como rendimento do trabalho ou do capital. Equivale ao rendimento obtido pelos empregadores, em firmas não constituídas, e pelos trabalhadores por conta própria. 
Obtemos $\tau_{k}=26,11 \%$. Quanto à tributação sobre a produção $\left(\tau_{j}\right)$, basta dividir a participação da arrecadação tributária sobre a produção por setor, obtido das Contas Nacionais, pela participação do produto do setor no PIB. Os resultados são mostrados na Tabela A.l do Anexo.

\subsection{Estoque de Capital, Salários e Transferências}

Para a determinação do estoque de capital $k$, basta igualar a participação da renda do capital no produto com o rendimento bruto do capital, conforme equação abaixo:

$$
k=\frac{\sum_{j=1}^{57}\left(1-\tau_{j}+\alpha_{j}^{e} \tau_{j}\right) \alpha_{j} p_{j} y_{j}}{\left(1+\tau_{k}\right) \cdot r} Y=202,25
$$

Calcula-se o salário usando a Equação (3) da escolha trabalho-lazer:

$$
w=\frac{\gamma \cdot C}{(1-h)}=157,15
$$

As transferências do governo para as famílias foram calculadas usando a restrição orçamentária do governo, Equação (13):

$$
T_{t}=\sum_{j=1}^{58} \tau_{j t}\left(1-\alpha_{j}^{e}\right) p_{j t} y_{j t}+\tau_{h t} w_{t} h_{t}+\tau_{k t} r_{t} k_{t}-g_{t}=14,71
$$

4.4 Parâmetros de Preferências, Depreciação e Produção do Bem Final

Para o cálculo do peso do lazer na função utilidade, $\tilde{a}$, utilizou-se das Equações (16), (4), (7) e (8), de forma a se obter a expressão acima: 


$$
\gamma=\frac{(1-h)}{\left(1+\tau_{h}\right) \frac{c}{Y} h} \sum_{j=1}^{57}\left(1-\tau_{j}+\alpha_{j}^{e} \tau_{j}\right) \cdot\left(1-\alpha_{j}\right) p_{j} y_{j}=2,0041
$$

Quanto à taxa de desconto intertemporal, utilizando a Equação (3), obtém-se $\beta=0,9661$. A depreciação pode ser obtida através da divisão da relação investimento/PIB pela razão capital/produto, calculado em $\delta=10,25 \%$.

O parâmetro $\lambda_{f}$ está diretamente ligado à elasticidade de substituição entre os bens intermediários na função de produção do bem final. Adotou-se $\lambda_{f}=1,85$, uma das estimativas adotadas pela literatura internacional conforme Christiano, Eichenbaum e Evans (2005).

\subsection{Variáveis das Firmas Intermediárias}

Em relação às firmas intermediárias, iniciamos com o cálculo do estoque de capital por setor, que pode ser obtido da distribuição do produto setorial em relação ao PIB conseguido nas Contas Nacionais (Tabela A.1) em conjunto com as Equações (7) e (8), com a seguinte expressão:

$$
k_{j}=\frac{\left(1-\tau_{j}+\alpha_{j}^{e} \tau_{j}\right) \alpha_{j} p_{j} y_{j}}{\left(1+\tau_{k}\right) \cdot r}
$$

O trabalho por setor pode ser calculado usando as Equações (7) e (8), obtendo-se a equação:

$$
h_{j}=\frac{\left(1+\tau_{k}\right) \cdot r}{\left(1+\tau_{h}\right) \cdot w} \cdot \frac{1-\alpha_{j}}{\alpha_{j}} \cdot k_{j}
$$


A produtividade de cada setor é calculada a partir da Equação (8), usando também as Equações (11), (20), (21), e (23), com a seguinte expressão:

$$
A_{j}=\frac{\left(1+\tau_{k}\right) \cdot r}{\left\{\left(1-\tau_{j}+\alpha_{j}^{e} \tau_{j}\right) \alpha_{j}\left[\frac{\left(1+\tau_{k}\right) \cdot r \cdot h \cdot\left(1-\alpha_{j}\right)}{Y \alpha_{j} \cdot \sum_{j=1}^{57}\left(1-\tau_{j}+\alpha_{j}^{e} \tau_{j}\right) \cdot\left(1-\alpha_{j}\right) p_{j} y_{j}}\right]^{\left(1-\alpha_{j}\right)}\left(\frac{\left(1-\alpha_{j}^{e}\right) p_{j} y_{j}}{Y}\right)^{1-\lambda_{f}}\right\}}
$$

De posse dos parâmetros já calibrados é possível determinar a produção do setor $j$ pela equação:

$$
y_{j}=A_{j} k_{j}^{\alpha_{j}} h_{j}^{1-\alpha_{j}}
$$

Finalmente, o nível de preços no setor $j$, pode ser calculado usando a Equação (7)

$$
p_{j t}=\frac{\left(1+\tau_{k t}\right) \cdot r_{t}}{\left(1-\tau_{j t}+\alpha_{j}^{e} \tau_{j}\right) A_{j} \alpha_{j} k_{j t}^{\alpha_{j}-1} h_{j t}^{1-\alpha_{j}}}
$$

Os resultados podem ser vistos na Tabela A.l no Anexo.

\section{Novo Regime Tributário}

A Medida Provisória no 540 de 02/08/2011 alterou provisoriamente (até o final de 2012) a incidência das contribuições previdenciárias patronais dos setores de vestuário e acessórios, outras confecções como roupa de cama e cobertores, calçados, móveis e softwares, em troca de aumentos, o que deixou de incidir sobre a folha de pagamento e passou a ser calculada sobre a receita bruta.

Considerou-se neste trabalho que tal cenário será não só mantido, mas também ampliado, a toda indústria brasileira. Assim, supõe-se que as contribuições previdenciárias patronais serão eliminadas 
para os setores industriais, aqui entendidos como os pertencentes aos códigos 201 (petróleo e gás natural) a 334 (móveis e indústrias diversas).

Para compensar a perda de arrecadação estima-se a necessidade de elevação da alíquota da COFINS como forma de manter a neutralidade tributária.

Segundo trabalho divulgado pela Receita Federal do Brasil em 2009, a contribuição patronal sobre os salários chegou ao equivalente a $\mathrm{R} \$$ 96 bilhões. Usando os dados das contas nacionais, estima-se que a indústria seja responsável por quase $\mathrm{R} \$ 25$ bilhões desse total. Assim, a perda de arrecadação estimada seria de $0,82 \%$ do PIB.

Como a COFINS arrecadou o equivalente a 3,94\% do PIB (R \$ 119 bilhões), segundo dados das Contas Nacionais, o incremento nas alíquotas da COFINS para recuperar a perda de R $\$ 24$ bilhões seria de aproximadamente 20\%. As atuais alíquotas de 7,6\% (sobre o valor adicionado) e $3 \%$ (sobre o faturamento) deveriam ser elevadas para algo em torno de $9,12 \%$ e 3,6\%.

Tais mudanças repercutem nas alíquotas tributárias do modelo. Serão agora duas alíquotas sobre a tributação do trabalho, uma de $18,98 \%$ para o setor industrial e a outra mantida em $30,12 \%$, refletindo a desoneração da contribuição patronal apenas para aquele setor. A segunda alteração é a elevação da alíquota sobre o valor adicionado, que passa a ser acrescida em mais $1,02 \%$ para todos os setores, refletindo a elevação da COFINS para todos, inclusive os importados. ${ }^{6}$ A Tabela A.1 apresenta as novas alíquotas. ${ }^{7}$

Espera-se algum ganho de eficiência econômica, com razoável reordenamento produtivo. É provável que a indústria aumente sua participação em relação aos serviços e agropecuária.

6 Excetuam-se apenas os setores de aluguéis, serviços domésticos, educação pública, saúde pública e administração pública e seguridade social, que atualmente já não são tributados pela COFINS.

7 Coluna "novo $\tau_{j}$ " na tabela do anexo. 


\section{Resultados}

\subsection{Resultados Agregados}

A mudança tributária proposta, troca da contribuição patronal sobre a folha de pagamento por uma elevação da COFINS, foi calculada de forma a ser neutra do ponto de vista da arrecadação. O Gráfico a seguir mostra a evolução no tempo das variáveis macroeconômicas ${ }^{8}$ agregadas e do bem-estar das famílias:
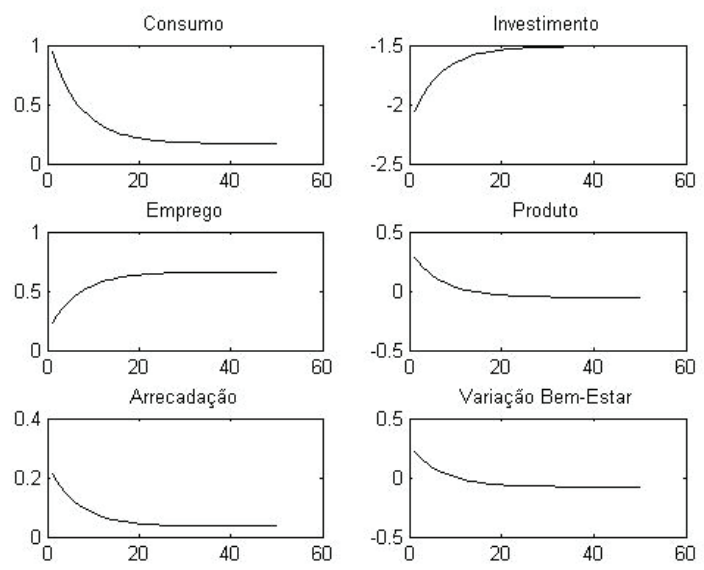

Gráfico 1 - Evolução dos agregados macroeconômicos

Como esperado, a redução da carga tributária sobre a renda elevou o emprego total, embora de forma modesta. Os efeitos de curto prazo são pequenos, da ordem de $0,3 \%$, mas que aumentam com o tempo, atingindo no longo prazo, pouco mais de $0,5 \%$. Como política para geração de empregos, a ideia de só desonerar a indústria não parece levar a uma maciça criação de postos de trabalho. Porém, há outros efeitos importantes que precisam ser considerados numa alteração tributária desta magnitude. Em primeiro lugar, do ponto de vista dos insumos na produção, o trabalho torna-se relativamente mais barato que o capital, o que induz a economia a utilizar relativamente mais trabalho e menos capital - observe a Equação (23), que mostra como a relação capital-trabalho depende da tributação do capital

\footnotetext{
8 Variação da variável macroeconômica em relação à situação atual em percentagem no eixo $y$ e no tempo, 50 períodos anuais no eixo $x$.
} 
(que não se alterou) e da tributação do trabalho (que diminui para a indústria). Aumentou-se o emprego, mas em contrapartida é possível que haja uma redução no capital, o que se reflete na diminuição do investimento. Um segundo efeito é que com o aumento das horas de trabalho, e, portanto, da renda, o consumo também se eleve.

A diminuição do investimento não é causada apenas pelo novo equilíbrio entre capital e trabalho, mas também pelo aumento da tributação sobre a produção. $\mathrm{Na}$ escolha do nível de capital ótimo das firmas, Equação (17), estas levam em consideração o nível de tributação sobre a produção. Como este aumentou, o capital utilizado pelas firmas tende a diminuir. No modelo, a redução do investimento foi de $1,5 \%$ no longo prazo, mas de quase $2 \%$ no curto prazo. Já o consumo é favorecido pela menor tributação sobre o trabalho, mas também é afetado de forma negativa pelo aumento da tributação sobre a produção. $\mathrm{O}$ primeiro efeito se mostra mais forte que o segundo, e o consumo apresenta modesto crescimento de quase $1 \%$ no curto prazo e $0,25 \%$ no longo prazo.

O aumento do emprego e a diminuição do uso do capital afetam o produto. Como o ajustamento negativo do capital leva muito mais tempo que o ajustamento positivo do trabalho, o produto cresce quase $0,5 \%$ no curto prazo. Porém, com o tempo, o capital vai lentamente diminuindo, de forma a anular o efeito da elevação do emprego. No longo prazo, a mudança tributária é quase neutra para o produto.

A arrecadação exibe um comportamento neutro em toda a sua trajetória. Há um leve incremento de $0,2 \%$ no curto prazo, que desaparece quando se olha o longo prazo. Tal resultado sugere que as alíquotas foram bem calibradas e que a elevação de $20 \%$ na COFINS parece suficiente para atender a desoneração na folha de pagamento da indústria.

Em relação ao bem-estar, dada a especificação da função utilidade - Equação (1) - o seu desempenho está atrelado ao comportamento do consumo e do emprego. Como houve variações positivas maiores no curto prazo, o bem-estar aumenta, ainda que de forma bem moderada em torno de $0,2 \%$. Já no longo prazo os efeitos das variações do consumo e do emprego se equivalem, anulando os ganhos sobre o bem-estar. 
Os resultados sugerem que a troca da contribuição patronal da indústria pelo aumento da COFINS não terá grandes efeitos macroeconômicos. A arrecadação permanece bem comportada em torno do seu nível pré-mudança, o que elimina maiores riscos fiscais. Ocorre um pequeno ganho no emprego e uma leve redução no uso do capital, mas sem efeitos mais robustos sobre o produto e o bem-estar.

\subsection{Resultados Setoriais}

Embora do ponto de vista macroeconômico os resultados sejam modestos, a proposta acarreta grandes variações na produção setorial. De maneira geral, os setores industriais passam a ser menos tributados, uma vez que se beneficiam integralmente da redução da tributação sobre a folha e incorrem em apenas parte do custo do aumento da tributação sobre a produção. Em contrapartida, os setores de serviços e agropecuária passam a ser mais tributados do que o são na situação atual. Esta realocação da tributação promove a redistribuição do produto e do emprego entre os diversos setores. No longo prazo, os setores com maior crescimento do produto foram todos industriais: Cimento, $+9,27 \%$, Outros Equipamentos de Transporte, $+6,98 \%$, Defensivos Agrícolas, $+6,32 \%$, Fumo, +5,66\%, Peças e Acessórios para Veículos Automotores, +5,08\% e Artigos de Borracha e Plástico, $+5,05 \%$. Na verdade, quase todos os setores industriais apresentaram expansão na produção. ${ }^{9}$

Já os setores mais prejudicados foram principalmente os de serviços: Produção e Distribuição de água, Gás e Esgoto, -1,74\%, Serviços de Informação, -1,70\%, Atividade Imobiliária, -1,54\%, Intermediação Financeira, Seguros e Previdência Complementar, -1,43\% e Serviços Prestados as Famílias, -1,42\%. Não houve nenhum setor de serviços que tenha apresentado crescimento. O setor agropecuário também apresentou perdas na ordem de $1 \%$, enquanto o setor industrial aumenta a sua participação no PIB, passando dos atuais 27,91\% (Contas Nacionais 2008) para $28,68 \%$, enquanto o setor de serviços diminui de $66,19 \%$ para $65,49 \%$ e o setor agropecuário de $5,90 \%$ para $5,84 \%$. Os gráficos ${ }^{10}$ a seguir ilustram o comportamento do produto.

\footnotetext{
9 As três únicas exceções foram Produtos e Preparados Químicos Diversos, -0,94\%, Fabricação de Resinas e Elastômeros, - $0,46 \%$ e Eletrodomésticos, - $0,46 \%$.

10 (variação do produto em relação à situação atual em percentagem - eixo $y$ ) no tempo (50 períodos anuais - eixo $x$ ) em setores selecionados.
} 

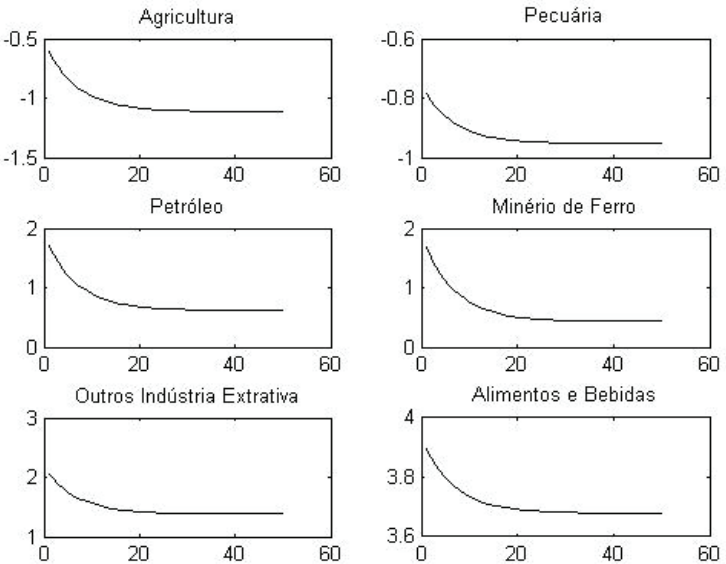

Gráfico 2 - Evolução da produção setorial (I)
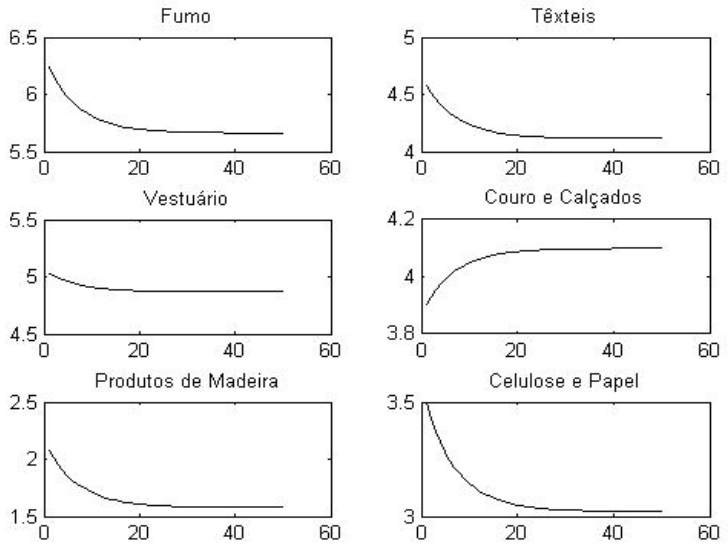

Gráfico 3 - Evolução da produção setorial (II) 

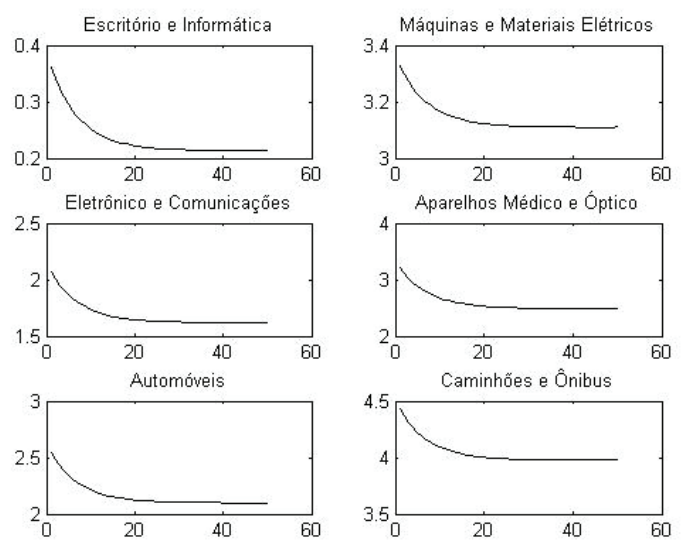

Gráfico 4 - Evolução da produção setorial (III)
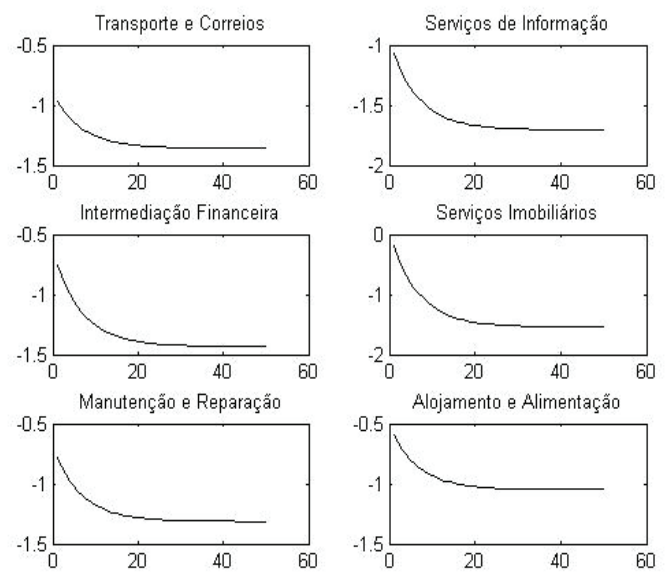

Gráfico 5 - Evolução da produção setorial (IV)

A redistribuição da produção tem efeito direto sobre o emprego, com migração para os setores industriais, em detrimento dos setores de serviços e agropecuário. A próxima tabela detalha a variação do emprego por setor no longo prazo em relação à situação antes da reforma. 
Tabela 2 - Variação do emprego

\begin{tabular}{|c|c|c|c|c|c|}
\hline Setor & Variação & Setor & Variação & Setor & Variação \\
\hline $\begin{array}{l}\text { Agricultura, } \\
\text { silvic., exploração } \\
\text { florestal. }\end{array}$ & $-2,44 \%$ & $\begin{array}{l}\text { Perfumaria, higiene } \\
\text { e limpeza. }\end{array}$ & $7,61 \%$ & $\begin{array}{l}\text { Móveis e } \\
\text { produtos das } \\
\text { indústrias } \\
\text { diversas }\end{array}$ & $10,34 \%$ \\
\hline Pecuária e pesca & $-2,17 \%$ & $\begin{array}{l}\text { Tintas, vernizes, } \\
\text { esmaltes e lacas. }\end{array}$ & $10,41 \%$ & $\begin{array}{l}\text { Eletricidade e } \\
\text { gás, água, esgoto } \\
\text { e limpeza urbana. }\end{array}$ & $-3,55 \%$ \\
\hline $\begin{array}{c}\text { Petróleo e gás } \\
\text { natural }\end{array}$ & $8,74 \%$ & $\begin{array}{l}\text { Produtos e preparados } \\
\text { químicos diversos }\end{array}$ & $2,20 \%$ & Construção & $-2,54 \%$ \\
\hline Minério de ferro & $9,06 \%$ & $\begin{array}{l}\text { Artigos de borracha } \\
\text { e plástico }\end{array}$ & $14,01 \%$ & Comércio & $-2,48 \%$ \\
\hline $\begin{array}{c}\text { Outros da } \\
\text { indústria extrativa }\end{array}$ & $8,62 \%$ & Cimento & $24,87 \%$ & $\begin{array}{c}\text { Transporte, } \\
\text { armazenagem e } \\
\text { correio. }\end{array}$ & $-2,89 \%$ \\
\hline $\begin{array}{l}\text { Alimentos e } \\
\text { bebidas }\end{array}$ & $11,33 \%$ & $\begin{array}{l}\text { Outros produtos de } \\
\text { minerais não metálicos. }\end{array}$ & $10,55 \%$ & $\begin{array}{l}\text { Serviços de } \\
\text { informação }\end{array}$ & $-3,51 \%$ \\
\hline Produtos do fumo & $16,73 \%$ & $\begin{array}{c}\text { Fabricação de aço } \\
\text { e derivados }\end{array}$ & $9,29 \%$ & $\begin{array}{l}\text { Intermediação } \\
\text { financeira e } \\
\text { seguros }\end{array}$ & $-3,01 \%$ \\
\hline Têxteis & $13,17 \%$ & $\begin{array}{l}\text { Metalurgia de metais } \\
\text { não ferrosos. }\end{array}$ & $7,34 \%$ & $\begin{array}{l}\text { Serviços } \\
\text { imobiliários }\end{array}$ & $-3,17 \%$ \\
\hline $\begin{array}{c}\text { Artigos do } \\
\text { vestuário e acess. }\end{array}$ & $13,46 \%$ & $\begin{array}{l}\text { Produtos de metal - } \\
\text { exclusive máquinas } \\
\text { e equipamentos }\end{array}$ & $11,57 \%$ & Aluguéis & $-0,31 \%$ \\
\hline $\begin{array}{c}\text { Artefatos de } \\
\text { couro e calçados }\end{array}$ & $10,52 \%$ & $\begin{array}{l}\text { Máquinas e } \\
\text { equipamentos. }\end{array}$ & $12,16 \%$ & $\begin{array}{l}\text { Serviços de } \\
\text { manut. e } \\
\text { reparação }\end{array}$ & $-2,80 \%$ \\
\hline $\begin{array}{l}\text { Produtos de } \\
\text { madeira }\end{array}$ & $8,31 \%$ & Eletrodomésticos & $3,79 \%$ & $\begin{array}{l}\text { Serviços de aloj. } \\
\text { e alimentação }\end{array}$ & $-2,33 \%$ \\
\hline $\begin{array}{l}\text { Celulose e } \\
\text { produtos de papel }\end{array}$ & $11,04 \%$ & $\begin{array}{c}\text { Máquinas para escritório } \\
\text { e informática }\end{array}$ & $4,30 \%$ & $\begin{array}{l}\text { Serviços } \\
\text { prestados às } \\
\text { empresas }\end{array}$ & $-2,30 \%$ \\
\hline $\begin{array}{l}\text { Jornais, revistas, } \\
\text { discos. }\end{array}$ & $8,87 \%$ & $\begin{array}{l}\text { Máquinas, aparelhos e } \\
\text { materiais elétricos. }\end{array}$ & $10,19 \%$ & $\begin{array}{l}\text { Educação } \\
\text { mercantil }\end{array}$ & $-2,79 \%$ \\
\hline $\begin{array}{c}\text { Refino de } \\
\text { petróleo e coque }\end{array}$ & $8,45 \%$ & $\begin{array}{l}\text { Material eletrônico } \\
\text { e equipamentos de } \\
\text { comunicações }\end{array}$ & $8,17 \%$ & Saúde mercantil & $-2,54 \%$ \\
\hline Álcool & $8,02 \%$ & $\begin{array}{l}\text { Aparelhos/instrumentos } \\
\text { médico-hospitalar, } \\
\text { medida e óptico. }\end{array}$ & $10,99 \%$ & $\begin{array}{l}\text { Serviços } \\
\text { prestados } \\
\text { às famílias e } \\
\text { associativas }\end{array}$ & $-3,03 \%$ \\
\hline $\begin{array}{l}\text { Produtos } \\
\text { químicos }\end{array}$ & $13,44 \%$ & $\begin{array}{c}\text { Automóveis, camionetas } \\
\text { e utilitários. }\end{array}$ & $9,11 \%$ & $\begin{array}{c}\text { Serviços } \\
\text { domésticos }\end{array}$ & $-0,30 \%$ \\
\hline $\begin{array}{l}\text { Fabricação } \\
\text { de resina e } \\
\text { elastômeros }\end{array}$ & $3,51 \%$ & Caminhões e ônibus & $12,85 \%$ & Educação pública & $-0,31 \%$ \\
\hline $\begin{array}{c}\text { Produtos } \\
\text { farmacêuticos }\end{array}$ & $9,73 \%$ & $\begin{array}{c}\text { Peças e acessórios para } \\
\text { veículos automotores }\end{array}$ & $13,86 \%$ & Saúde pública & $-0,31 \%$ \\
\hline $\begin{array}{l}\text { Defensivos } \\
\text { agrícolas }\end{array}$ & $17,82 \%$ & $\begin{array}{l}\text { Outros equipamentos de } \\
\text { transporte }\end{array}$ & $17,46 \%$ & $\begin{array}{l}\text { Adm. Pública e } \\
\text { Seguridade Social }\end{array}$ & $-0,32 \%$ \\
\hline
\end{tabular}

Fonte: Elaboração dos autores. 
A desoneração da folha de pagamento tem um forte efeito sobre o emprego na indústria com crescimento bastante substancial em muitos setores. Todos os setores industriais apresentam aumento do emprego e em todos os setores de serviços e agropecuária ocorre queda. Novamente, as magnitudes são desproporcionais, com os ganhos muito mais elevados em termos absolutos do que as quedas.

\section{Conclusões}

A indústria brasileira tem enfrentado sérias dificuldades para manter sua competitividade, afetada pela expansão das importações e pela perda de mercados externos. O saldo comercial brasileiro na indústria de transformação tem ficado cada vez mais negativo. No primeiro trimestre de 2008, o saldo era de -US\$ 204 milhões; esse saldo negativo caiu para -US\$7,1 bilhões e quase -US\$ 10 bilhões em igual período de 2010 e 2011 respectivamente.

Visando minimizar as dificuldades que se colocam a indústria, o governo brasileiro lançou recentemente o programa Brasil Maior, voltado para incrementar a competitividade da indústria nacional. Entre outras ações está a alteração provisória e experimental (até o final de 2012) da incidência das contribuições previdenciárias (patronal) dos setores de vestuário e acessórios, calçados, móveis e softwares, que deixará de incidir sobre a folha de pagamento e passará a ser calculada sobre a receita bruta (Medida Provisória no 540 de 02/08/2011).

O artigo buscou estimar os resultados da ampliação da eliminação da contribuição patronal sobre a folha de pagamento para todo o setor industrial, tendo como contrapartida o aumento na tributação sobre o consumo.

Para a análise do impacto destas mudanças sobre a economia, foi construído um modelo de equilíbrio geral neoclássico, contemplando uma família representativa e o lado produtivo com 57 firmas mais importações, representando cada uma um setor da economia. Esta economia foi calibrada com dados das Contas Nacionais 2008. Para a efetivação das simulações, calculou-se que seria necessária uma elevação de $20 \%$ nas alíquotas da COFINS para se manter a neutralidade na arrecadação. 
Os resultados sugerem que do ponto de vista agregado não haverá grandes consequências macroeconômicas, apenas a expansão do emprego, mas sem afetar significativamente produto, consumo, arrecadação e investimento. Do lado setorial as modificações são muito mais intensas, com a reforma beneficiando a maioria dos setores industriais, atualmente muito mais tributado do que os demais segmentos da economia nacional. Porém, o balanceamento entre ganhadores e perdedores é bastante assimétrico, em razão da concentração da desoneração em determinados setores, e pela dispersão dos custos associados ao incremento da tributação sobre o consumo. Enquanto os principais ganhadores experimentam aumentos de mais de $5 \%$ no produto, os perdedores apresentam reduções máximas em torno de $1,5 \%$. Do lado do emprego, o setor industrial apresenta expansão ainda mais elevada, com alguns setores crescendo mais de 10\% como Artigos de Borracha e Plástico e Outros Equipamentos de Transporte. Os demais setores apresentam quedas no emprego com valores máximos em torno de 3\%.

Por fim, é importante ressaltar que várias ineficiências e incongruências do regime de tributação brasileiro não foram tratadas neste trabalho. Por exemplo, os inúmeros tributos e alíquotas diferentes, o emaranhado de legislações e a falta de transparência não foram objeto deste estudo, mas devem permanecer na agenda de mudanças. Reformar e melhorar o nosso complexo sistema tributário permanece como um grande desafio a ser enfrentado por toda a sociedade.

\section{Referências}

ALTIG, D., AUERBACH, A.J., KOTLIKOFF, L., SMETTERS, K. E WALLISER, J. Simulating Fundamental Tax Reform in the United States. American Economic Review, v.91, n.3, p.574-595, 2001.

ARAÚJO, C. H. V., FERREIRA, P. C. Reforma Tributária, Efeitos Alocativos e Impactos de Bem-Estar. Revista Brasileira de Economia, Rio de Janeiro, v.53, n.2, 1999.

AUERBACH, A.; KOTLIKOFF, L. Dynamic Fiscal Policy. Cambridge University Press, 1987.

BOVENBERG, A.L. Indirect Taxation in Developing Countries: a Computable General Equilibrium Approach. IMF Staff Papers, Washington, D.C., v.34, p.333-73, 1987.

CHRISTIANO, L.; EICHENBAUM, M.; EVANS, C. Nominal Rigidities and the Dynamic Effects of a Shock to Monetary Policy. Journal of Political Economy, v.113, n.1, p. 2-45, 2005.

CONFEDERAÇÃO NACIONAL DA INDÚSTRIA - CNI. Especial China. Sondagem Especial, Ano 9, Número 1, 1 de fevereiro de 2011. Disponível em: www.cni.org.br

FULLERTON, D. On the Possibility of an Inverse Relationship between Tax Rates and Government Revenues. Journal of Public Economics, v.19, p.3-22, 1982. 
FULLERTON, D., ROGERS, D. L. Who Bears the Lifetime Tax Burden? Brookings Institution, 1993.

INSTITUTO BRASILEIRO DE GEOGRAFIA E ESTATÍSTICA(IBGE). Sistema de Contas Nacionais 2006 - 2008. Rio de Janeiro, 2009.

. Rendimento do Trabalho e Ocupação. Notas Metodológicas n.7, Sistema de Contas Nacionais Brasil-Referência 2000, 2006.

LEVY, M., NONNENBERG, L., DE NEGRI, F. O Crescimento Econômico e a Competitividade Chinesa. IPEA, Boletim de Conjuntura, n.73, p. 81-88, 2006.

NORONHA, E.; DE NEGRI, F.; ARTUR, K. Custos do Trabalho, Direitos Sociais e Competitividade Industrial, in J. A. de Negri, F. de Negri e D. Coelho (orgs.), Tecnologia, Exportação e Emprego. Brasília, IPEA, 2006.

PAES, N. Reforma Tributária - Os Efeitos Macroeconômicos e Setoriais da PEC 233/2008. Estudos Econômicos, vol.41, n.2, 2011.

PAES, N.; BUGARIN, M. Reforma Tributária: Impactos Distributivos, sobre o Bem-Estar e a Progressividade. Revista Brasileira de Economia, vol.60, n.2, 2006.

PEREIRA, R.; FERREIRA, P. C. Avaliação dos Impactos Macroeconômicos e do Bem-Estar da Reforma Tributária no Brasil. XXXVII Encontro Nacional de Economia, Foz do Iguaçu, 2009.

SALAMI, C. R.; FOCHEZATTO, A. Avaliando os Impactos de Políticas Tributárias sobre a Economia Brasileira com Base em um Modelo de Equilíbrio Geral de Gerações Sobrepostas. Revista Brasileira de Economia, v. 63, n.3, p.299-314, 2009.

SHOVEN, J. E WHALLEY, J. Applied General-Equilibrium Models of Taxation and International Trade: An Introduction and a Survey. Journal of Economic Literature, v.23, p.1007-1051, 1984.

TAYLOR, P. M. Developing Policy Analisys of Fundamental Tax Reform. The American Economic Review, v.87, n.2, p.143-146, Papers and Proceedings of the Hundred and Fourth Annual Meeting of the American Economic Association. May 1997. 


\section{ANEXO}

Tabela A.1 - Distribuição das variáveis das firmas intermediárias

\begin{tabular}{|c|c|c|c|c|c|c|c|c|c|c|}
\hline Setor & $\begin{array}{l}\text { V.A. } \\
(\% \mathrm{PIB})^{11}\end{array}$ & $\begin{array}{l}\text { Arrec. } \\
(\% \mathrm{PIB})\end{array}$ & $\alpha_{j}$ & $\tau_{j}$ & $h_{j}$ & $k_{j}$ & $A_{j}$ & $y_{j}$ & $p_{j}$ & $\begin{array}{l}\text { Novo } \\
\tau_{j}\end{array}$ \\
\hline $\begin{array}{l}\text { Agricultura, silvicultura, } \\
\text { exploração florestal }\end{array}$ & 3,58 & 0,23 & 0,49 & $7,54 \%$ & 0,0083 & 9,50 & 0,70 & 0,1846 & 0,14 & $8,57 \%$ \\
\hline Pecuária e pesca & 1,79 & 0,23 & 0,31 & $12,72 \%$ & 0,0053 & 2,77 & 1,61 & 0,0580 & 0,01 & $13,74 \%$ \\
\hline Petróleo e gás natural & 1,79 & 0,02 & 0,80 & $1,29 \%$ & 0,0017 & 8,16 & 0,03 & 0,0499 & 0,17 & $2,31 \%$ \\
\hline Minério de ferro & 0,78 & 0,04 & 0,89 & $17,43 \%$ & 0,0004 & 3,87 & 0,00 & 0,0045 & 0,71 & $18,45 \%$ \\
\hline $\begin{array}{l}\text { Outros da indústria } \\
\text { extrativa }\end{array}$ & 0,29 & 0,04 & 0,57 & $15,98 \%$ & 0,0005 & 0,84 & 0,05 & 0,0019 & 0,11 & $17,00 \%$ \\
\hline Alimentos e bebidas & 3,14 & 1,22 & 0,33 & $44,19 \%$ & 0,0063 & 3,62 & 2,98 & 0,1488 & 0,12 & $45,21 \%$ \\
\hline Produtos do fumo & 0,34 & 0,22 & 0,51 & $79,86 \%$ & 0,0003 & 0,34 & 0,21 & 0,0022 & 0,20 & $80,88 \%$ \\
\hline Têxteis & 0,58 & 0,09 & 0,45 & $15,85 \%$ & 0,0013 & 1,27 & 0,23 & 0,0068 & 0,06 & $16,87 \%$ \\
\hline $\begin{array}{l}\text { Artigos do vestuário e } \\
\text { acessórios }\end{array}$ & 0,63 & 0,12 & 0,29 & $18,59 \%$ & 0,0018 & 0,88 & 0,78 & 0,0086 & 0,01 & $19,61 \%$ \\
\hline $\begin{array}{l}\text { Artefatos de couro e } \\
\text { calçados }\end{array}$ & 0,36 & 0,10 & 0,11 & $34,53 \%$ & 0,0011 & 0,16 & 1,34 & 0,0026 & 0,17 & $35,55 \%$ \\
\hline Produtos de madeira & 0,36 & 0,06 & 0,48 & $21,15 \%$ & 0,0008 & 0,84 & 0,12 & 0,0026 & 0,18 & $22,17 \%$ \\
\hline $\begin{array}{c}\text { Celulose e produtos de } \\
\text { papel }\end{array}$ & 0,62 & 0,16 & 0,46 & $31,31 \%$ & 0,0012 & 1,21 & 0,24 & 0,0069 & 0,17 & $32,33 \%$ \\
\hline Jornais, revistas, discos & 0,70 & 0,09 & 0,53 & $13,34 \%$ & 0,0014 & 1,87 & 0,16 & 0,0104 & 0,00 & $14,36 \%$ \\
\hline Refino de petróleo e coque & 3,04 & 0,75 & 0,72 & $26,28 \%$ & 0,0032 & 9,50 & 0,15 & 0,1482 & 0,07 & $27,30 \%$ \\
\hline Álcool & 0,39 & 0,06 & 0,66 & $18,20 \%$ & 0,0006 & 1,25 & 0,04 & 0,0031 & 0,13 & $19,22 \%$ \\
\hline Produtos químicos & 0,46 & 0,09 & 0,49 & $19,89 \%$ & 0,0009 & 1,05 & 0,15 & 0,0045 & 0,06 & $20,91 \%$ \\
\hline $\begin{array}{l}\text { Fabricação de resina e } \\
\text { elastômeros }\end{array}$ & 0,15 & 0,03 & 0,36 & $25,99 \%$ & 0,0003 & 0,24 & 0,13 & 0,0005 & 0,09 & $27,01 \%$ \\
\hline Produtos farmacêuticos & 0,72 & 0,20 & 0,57 & $28,04 \%$ & 0,0011 & 1,75 & 0,14 & 0,0109 & 0,03 & $29,06 \%$ \\
\hline Defensivos agrícolas & 0,14 & 0,05 & 0,48 & $33,51 \%$ & 0,0002 & 0,26 & 0,08 & 0,0005 & 0,04 & $34,54 \%$ \\
\hline $\begin{array}{l}\text { Perfumaria, higiene e } \\
\text { limpeza }\end{array}$ & 0,52 & 0,20 & 0,52 & $39,63 \%$ & 0,0008 & 0,97 & 0,19 & 0,0059 & 0,02 & $40,65 \%$ \\
\hline $\begin{array}{c}\text { Tintas, vernizes, esmaltes } \\
\text { e lacas }\end{array}$ & 0,12 & 0,02 & 0,37 & $17,08 \%$ & 0,0003 & 0,22 & 0,12 & 0,0004 & 0,03 & $18,10 \%$ \\
\hline $\begin{array}{l}\text { Produtos e preparados } \\
\text { químicos diversos }\end{array}$ & 0,16 & 0,04 & 0,31 & $31,93 \%$ & 0,0004 & 0,21 & 0,22 & 0,0006 & 0,10 & $32,95 \%$ \\
\hline $\begin{array}{l}\text { Artigos de borracha e } \\
\text { plástico }\end{array}$ & 0,66 & 0,13 & 0,32 & $20,28 \%$ & 0,0018 & 0,97 & 0,67 & 0,0088 & 0,06 & $21,30 \%$ \\
\hline Cimento & 0,12 & 0,05 & 0,59 & $37,76 \%$ & 0,0001 & 0,24 & 0,04 & 0,0004 & 0,01 & $38,78 \%$ \\
\hline $\begin{array}{c}\text { Outros produtos de } \\
\text { minerais não metálicos }\end{array}$ & 0,59 & 0,13 & 0,37 & $23,95 \%$ & 0,0014 & 0,98 & 0,45 & 0,0071 & 0,07 & $24,97 \%$ \\
\hline $\begin{array}{l}\text { Fabricação de aço e } \\
\text { derivados }\end{array}$ & 1,16 & 0,15 & 0,71 & $16,08 \%$ & 0,0014 & 4,14 & 0,05 & 0,0218 & 0,20 & $17,10 \%$ \\
\hline $\begin{array}{l}\text { Metalurgia de metais não } \\
\text { ferrosos }\end{array}$ & 0,35 & 0,05 & 0,49 & $21,12 \%$ & 0,0008 & 0,86 & 0,09 & 0,0022 & 0,26 & $22,14 \%$ \\
\hline $\begin{array}{l}\text { Produtos de metal - } \\
\text { exclusive máquinas e } \\
\text { equipamentos }\end{array}$ & 1,13 & 0,23 & 0,46 & $20,97 \%$ & 0,0023 & 2,39 & 0,42 & 0,0240 & 0,04 & $22,00 \%$ \\
\hline Máquinas e equipamentos. & 1,41 & 0,42 & 0,35 & $32,84 \%$ & 0,0031 & 1,99 & 1,15 & 0,0344 & 0,10 & $33,86 \%$ \\
\hline Eletrodomésticos & 0,30 & 0,18 & 0,40 & $62,83 \%$ & 0,0003 & 0,28 & 0,40 & 0,0021 & 0,03 & $63,85 \%$ \\
\hline $\begin{array}{l}\text { Máquinas para escritório e } \\
\text { informática }\end{array}$ & 0,15 & 0,05 & 0,29 & $35,36 \%$ & 0,0004 & 0,17 & 0,28 & 0,0006 & 0,01 & $36,38 \%$ \\
\hline $\begin{array}{l}\text { Máquinas, aparelhos e } \\
\text { materiais elétricos }\end{array}$ & 0,62 & 0,18 & 0,33 & $32,60 \%$ & 0,0014 & 0,81 & 0,67 & 0,0075 & 0,09 & $33,62 \%$ \\
\hline
\end{tabular}




\section{(Continuação)}

\begin{tabular}{|c|c|c|c|c|c|c|c|c|c|c|}
\hline $\begin{array}{l}\text { Material eletrônico } \\
\text { e equipamentos de } \\
\text { comunicações }\end{array}$ & 0,47 & 0,15 & 0,45 & $34,75 \%$ & 0,0009 & 0,83 & 0,25 & 0,0047 & 0,07 & $35,77 \%$ \\
\hline $\begin{array}{c}\text { Aparelhos/instrumentos } \\
\text { médico-hospitalar, medida } \\
\text { e óptico }\end{array}$ & 0,34 & 0,08 & 0,60 & $23,70 \%$ & 0,0005 & 0,91 & 0,06 & 0,0027 & 0,04 & $24,72 \%$ \\
\hline $\begin{array}{l}\text { Automóveis, camionetas e } \\
\text { utilitários }\end{array}$ & 1,42 & 0,54 & 0,45 & $41,49 \%$ & 0,0024 & 2,29 & 0,69 & 0,0358 & 0,08 & $42,51 \%$ \\
\hline Caminhões e ônibus & 0,41 & 0,10 & 0,45 & $29,63 \%$ & 0,0008 & 0,79 & 0,18 & 0,0031 & 0,18 & $30,65 \%$ \\
\hline $\begin{array}{l}\text { Peças e acessórios para } \\
\text { veículos automotores }\end{array}$ & 0,78 & 0,15 & 0,29 & $21,21 \%$ & 0,0022 & 1,06 & 0,86 & 0,0113 & 0,11 & $22,23 \%$ \\
\hline $\begin{array}{l}\text { Outros equipamentos de } \\
\text { transporte }\end{array}$ & 0,36 & 0,08 & 0,26 & $30,13 \%$ & 0,0010 & 0,41 & 0,46 & 0,0022 & 0,29 & $31,15 \%$ \\
\hline $\begin{array}{l}\text { Móveis e produtos das } \\
\text { indústrias diversas }\end{array}$ & 0,84 & 0,25 & 0,52 & $30,68 \%$ & 0,0014 & 1,77 & 0,25 & 0,0140 & 0,04 & $31,70 \%$ \\
\hline $\begin{array}{l}\text { Eletricidade e gás, água, } \\
\text { esgoto e limpeza urbana }\end{array}$ & 3,78 & 1,23 & 0,76 & $32,51 \%$ & 0,0030 & 11,21 & 0,15 & 0,2336 & 0,00 & $33,53 \%$ \\
\hline Construção & 4,35 & 0,29 & 0,53 & $6,64 \%$ & 0,0093 & 12,33 & 0,73 & 0,3007 & 0,01 & $7,66 \%$ \\
\hline Comércio & 12,07 & 1,56 & 0,47 & $15,35 \%$ & 0,0273 & 28,29 & 2,48 & 1,7278 & 0,16 & $16,37 \%$ \\
\hline $\begin{array}{c}\text { Transporte, armazenagem } \\
\text { e correio }\end{array}$ & 4,82 & 0,70 & 0,43 & $14,94 \%$ & 0,0115 & 10,18 & 1,70 & 0,3577 & 0,03 & $15,96 \%$ \\
\hline Serviços de informação & 4,37 & 1,32 & 0,57 & $30,35 \%$ & 0,0065 & 9,96 & 0,74 & 0,3045 & 0,01 & $31,37 \%$ \\
\hline $\begin{array}{c}\text { Intermediação financeira } \\
\text { e seguros }\end{array}$ & 6,33 & 0,75 & 0,59 & $12,01 \%$ & 0,0112 & 18,95 & 0,68 & 0,6019 & 0,01 & $13,03 \%$ \\
\hline Serviços imobiliários & 1,86 & 0,07 & 0,96 & $4,11 \%$ & 0,0004 & 9,85 & 0,01 & 0,0613 & 0,02 & $5,13 \%$ \\
\hline Aluguéis & 5,02 & 0,00 & 0,04 & $0,00 \%$ & 0,0234 & 1,26 & 14,19 & 0,3947 & 0,00 & $0,00 \%$ \\
\hline $\begin{array}{l}\text { Serviços - manutenção e } \\
\text { reparação }\end{array}$ & 0,92 & 0,06 & 0,51 & $6,56 \%$ & 0,0021 & 2,51 & 0,23 & 0,0171 & 0,00 & $7,58 \%$ \\
\hline $\begin{array}{l}\text { Serviços de alojamento e } \\
\text { alimentação }\end{array}$ & 1,87 & 0,38 & 0,46 & $22,00 \%$ & 0,0039 & 4,01 & 0,60 & 0,0590 & 0,09 & $23,02 \%$ \\
\hline $\begin{array}{l}\text { Serviços prestados às } \\
\text { empresas }\end{array}$ & 4,44 & 0,35 & 0,37 & $8,61 \%$ & 0,0126 & 8,74 & 2,04 & 0,2892 & 0,10 & $9,63 \%$ \\
\hline Educação mercantil & 0,97 & 0,07 & 0,01 & $7,27 \%$ & 0,0043 & 0,06 & 4,23 & 0,0189 & 0,00 & $8,29 \%$ \\
\hline Saúde mercantil & 1,74 & 0,20 & 0,28 & $11,38 \%$ & 0,0054 & 2,51 & 1,82 & 0,0556 & 0,00 & $12,40 \%$ \\
\hline Outros serviços & 2,11 & 0,27 & 0,27 & $13,00 \%$ & 0,0065 & 2,91 & 2,27 & 0,0788 & 0,01 & $14,02 \%$ \\
\hline Serviços Domésticos & 1,00 & 0,00 & 0,01 & $0,00 \%$ & 0,0048 & 0,06 & 4,02 & 0,0200 & 0,00 & $0,00 \%$ \\
\hline Educação pública & 3,21 & 0,00 & 0,05 & $0,00 \%$ & 0,0149 & 0,85 & 9,61 & 0,1726 & 0,00 & $0,00 \%$ \\
\hline Saúde pública & 1,67 & 0,00 & 0,05 & $0,00 \%$ & 0,0077 & 0,49 & 5,41 & 0,0515 & 0,00 & $0,00 \%$ \\
\hline $\begin{array}{l}\text { Administração pública e } \\
\text { seguridade social }\end{array}$ & 8,29 & 0,00 & 0,14 & $0,02 \%$ & 0,0349 & 6,55 & 13,98 & 0,9984 & 0,00 & $0,00 \%$ \\
\hline Importações & 5,80 & 1,58 & 0,00 & $27,19 \%$ & 0,0000 & 0,00 & 0,00 & 5,8000 & 0,00 & $28,21 \%$ \\
\hline
\end{tabular}

Fonte: Elaboração dos autores com dados das Contas Nacionais 2008.

${ }^{11}$ Em relação aos valores constantes das contas nacionais, foram efetuadas alterações no setor veículos, que estava com excedente operacional bruto negativo e caminhões, cujo excedente operacional bruto era inferior a $10 \%$ do valor adicionado. Nos dois casos considerou-se que a relação excedente operacional bruto por valor adicionado correspondia ao percentual médio observado nas contas nacionais. 